\title{
INFLUENCE OF INTERDISCIPLINARY COMMUNICATION OF CLASSICAL DISCIPLINES ON DEVELOPMENT OF PROFESSIONAL COMPETENCE OF STUDENTS OF MACHINE BUILDING SPECIALTIES
}

\author{
Elena V. Vasileva ${ }^{1}$, Oleg V. Zakharov ${ }^{2}$, Alevtina G. Kulagina ${ }^{3^{*}}$ \\ Oksana V. Sveklova ${ }^{4}$, Lyudmila V. Seliverstova ${ }^{5}$ \\ ${ }^{1}$ Senior lecturer, Chuvash State University, Russia, lenok-vasilek@inbox.ru \\ ${ }^{2}$ Ph.D, Full Professor, Yuri Gagarin State Technical University of Saratov, Russia, zov20@mail.ru \\ ${ }^{3}$ Assoc. Prof. Dr., Chuvash State University, Russia, agkulagina11@gmail.com \\ ${ }^{4}$ Senior teacher, Chuvash State University, Russia, sveklova.ok@yandex.ru \\ ${ }^{5}$ Assoc. Prof. Dr., Chuvash State University, Russia, sara-80@yandex.ru \\ ${ }^{*}$ Corresponding Author
}

\begin{abstract}
It is impossible to imagine the modern educational process without the interrelation between disciplines of different orientation. The necessity to introduce interdisciplinary integration arises in the process of forming the professional competence of students of machine building specialties already from the $1^{\text {st }}$ and 2 nd courses of higher schools. The introduction of contemporary teaching methods, their compilation with the classical methodology allows us to form an effective link between such classic subjects of engineering specialties as higher mathematics and theoretical mechanics studied at the machine building faculty of I.N.Ulyanov Chuvash State University. The article considers ways to introduce interdisciplinary communication in the educational process on the example of such basic subjects as "Mathematics" and "Theoretical mechanics". A problem in the course of "Theoretical mechanics" with a detailed study of the interdisciplinary relationship is analyzed.
\end{abstract}

Keywords: professional competence, interdisciplinary integration, higher mathematics, theoretical mechanics.

\section{INTRODUCTION}

The successful development of the country is currently based on a variety of factors, the professional compliance of specialists engaged in technically complex production facilities being one of them. According to the conditions of the labor market, the employer wants to get a highly qualified competent and erudite specialist -graduate from the University without retraining him, otherwise, this leads to additional financial costs, and most enterprises don't want to accept it. Some time before the qualification of graduates meant 
only "compliance" workplace, and students' training was limited to basic knowledge, skills and experience. Today the "competence" involves not only the acquisition of common knowledge, but in specific area it includes readiness to successfully implement one's skills, while improving quality and efficiency of the activities.

Modern requirements to education at all levels of the educational process implement a competency-based approach focused on the relationship between professional competence and the content of education. Using the definition given by A.V. Khutorskoy and other researchers (Khutorskoy, 2003, p. 56; Troeshestova, 2014, p. 167; Malysheva, 2013, p. 304; llina, 2018, p. 482) working in this field, one can understand the professional competence of students of a technical University as a formed association of personality qualities, which will help them to implement successfully their knowledge, skills and abilities into engineering in future.

The main characteristics of a highly qualified specialist acquired in the course of training at the University are the ability to think logically, analyze the problem and draw conclusions based on the analysis. The development of these mathematical and professional competencies in teaching classical disciplines is an urgent problem that many scientists are engaged in (Volodina, 2017, p. 112; Troeshestova, 2014, p. 133).

In the implementation of our educational programs, we consider competence to be an inseparable link between the process of mastering/obtaining theoretical knowledge in higher education and its practical application in solving applied problems. For example, in the process of solving the problem in dynamics of a material point and construct a mathematical model of this physical process we get the differential equation (problem in theoretical mechanics), and the ways and methods of solving the resulting equations - it is the task of higher mathematics, followed by interpretation of the obtained result and conclusion based on the data (problem in theoretical mechanics).

Under the concept of interdisciplinary integration, we understand the highest form of unity of goals, principles and meaning of education, creating a large-scale interconnection of all educational disciplines of the curriculum (Gartfelder, 2015, p. 33; Gartfelder, 2015, p. 195). Such an interpretation of this concept dictates that the process of developing professional competencies of students should start as early as in the 1st year in order for them to have formed a certain thinking and ability to solve the set professional tasks by the end of high school. In the machine building department, this can be achieved through cross-disciplinary communication and a close relationship "University-Enterprise", which makes it possible to hone the acquired knowledge, skills and abilities directly within the university and improve them at the enterprises.

Currently, high-quality technologies to develop interdisciplinary integration aimed at forming professional competence of students are not sufficiently worked out in education (Vasilyeva, 2015, p. 21; Perehozheva, 2012, p. 126). The laboratory work or, at least, calculation and graphic works would be a good help for this purpose. Unfortunately, there are no laboratory works for the disciplines "Mathematics" and "Theoretical mechanics" at the machine building faculty, and the number of calculation and graphic works is reduced to a minimum.

Due to the decrease of classroom work (Seliverstova, 2015, p. 152), students are given the necessary material to develop only certain competencies at lectures and in practical classes. However, the use of all possible information technologies (Brycheva, 2015, p. 175; Seliverstova, 2013, p. 272; Merlina, 2015, p. 60; Konstantinova, 2018, p. 129; Seliverstova, 2017, p. 182) allows you to conduct extracurricular creative work: solving multi-level tasks, professional-oriented tasks and case-tasks that relate to the "Own" level (Sinkina, 2012 , p. 112). In this regard, we believe that cross interaction between disciplines, development and implementation of technologies of interdisciplinary integration is becoming more and more relevant for the qualitative development of the necessary professional competencies (Mytnikova, 2018, p. 421).

\section{PROBLEM STATEMENT}

In I. N. Ulyanov Chuvash State University, the courses "Mathematics" and "Theoretical mechanics" are taught according to the curriculum for students of the machine building specialty in the $1^{\text {st }}$ and 2 nd years of study, so the interdisciplinary relationship and the formation of relevant competencies are most effectively monitored when studying these subjects' impact on the quality of education. The necessity to get fundamental knowledge in these disciplines is due to the fact that more highly specialized subjects such as "Machine parts", "Theory of mechanisms and machines", "Resistance of materials", etc., are entirely based on previously studied theoretical and practical material.

To investigate and resolve this problem, we used theoretical (research and generalization of pedagogical experience) and empirical (observation, testing, etc.) methods of pedagogical research. The most significant 
method of research for us was the method of expert assessments, based on borrowing pedagogical experience from colleagues of the older generation. As a result, the information obtained was analyzed and appropriate conclusions were drawn.

\section{THE ORETICAL PART AND PRACTICAL SIGNIFICANCE}

To educate a highly professional engineer, thorough assimilation of knowledge of classical subjects is of great importance, since it is impossible to carry out complex calculations and analysis without basic knowledge (Sinkina, 2011, p. 118). Special disciplines in mechanical engineering technology, processes and operations of shaping, and equipment of machine-building productions are based on basic disciplines (Zakharov, 2006, p. 152). And in the first year of the machine building faculty, subjects as" Mathematics "and "Theoretical mechanics" form this basis. According to the Federal State Educational Standard these disciplines are aimed at mastering the following competencies:

- GPC-1: ability to use the basic rules that operate in the process of manufacturing small machine building products of the required quality, of given quantity at the lowest cost of social labor.

- GPC-5: ability to solve standard tasks of professional activity on the basis of information and bibliographic culture with the use of information and communication technologies and taking into account the basic requirements of information security;

In recent years there is a tendency in the educational process that the number of hours allocated for an independent work of students (tests, calculation and graphic works, etc.), as well as the number of classroom hours have significantly decreased. Although, it is an independent work that allows you to get fully into the essence of the subject being studied. Both the number of classroom hours and the number of independent lectures at the machine building faculty, allocated for mastering professional competencies, according to the curriculum are as following:

- "Mathematics" has 96 hours of lectures, 128 hours of practical classes, 1 calculation and graphic work;

- "Theoretical mechanics" has 64 hours of lectures, 64 hours of practical classes, 2 calculation and graphic works.

The above mentioned number of hours is only enough for the immediate digestion of mathematical apparatus or to understand physical process. And due to the lack of training hours in the learning process, interaction and relationship of subjects with disciplines of senior courses are not accented or not mentioned. This leads to the fact that students do not understand the importance of the studied subjects, do not understand necessity of these subjects, because they do not catch the connection between them, and all this reduces interest and motivation. Let's consider an example of implementing an interdisciplinary communication based on a problem from the section of theoretical mechanics "Statics", studied by students of machine building faculties in the 2 nd term of the $1^{\text {st }}$ year (textbook by Meshchersky I. V. Collection of problems in theoretical mechanics. Moscow: Nauka Publ., 1981). By that time, the concepts of a vector, scalar and vector production of vectors had been studied in the discipline of "Higher mathematics", the concepts of the mechanical meaning of a vector product had been given, the concepts of matrices and determinants had been studied.

Problem condition: The rod $A B$ is held in an inclined position by two horizontal ropes $A D$ and $B C$. In this case, at point $A$, the rod rests at a vertical wall, where point $D$ is located, and at point $B$ the rod rests on a horizontal floor (Fig. 1). Points $A$ and $C$ lie on the same vertical. The weight of the rod is $8 \mathrm{~N}$. Friction at points $A$ and $B$ is negligible. It is necessary to check whether the rod can remain in balance, and determine the tension $T_{A}$ and $T_{B}$ of the ropes and the reaction of the support planes, if the angle $A B C=60^{\circ}$, angle $B C E=60^{\circ}$.

Mechanical part of the problem: students need to determine the forces acting on the rod and the reactions in the supports, set the directions of the corresponding vectors: $\vec{P}, \vec{R}_{A}, \vec{R}_{B}, \vec{T}_{A}, \vec{T}_{B}$ (Fig. 2). 


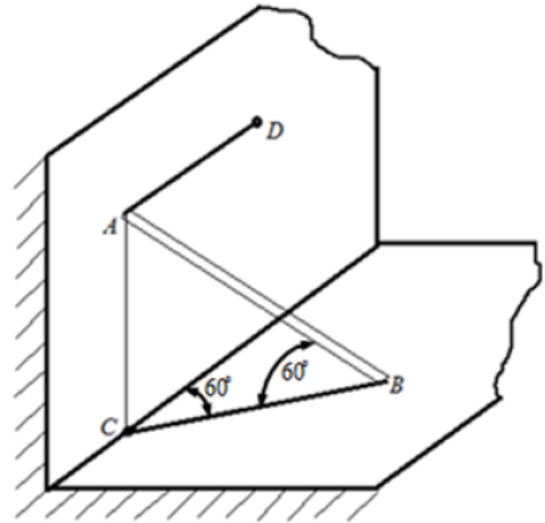

Fig.1. The given scheme

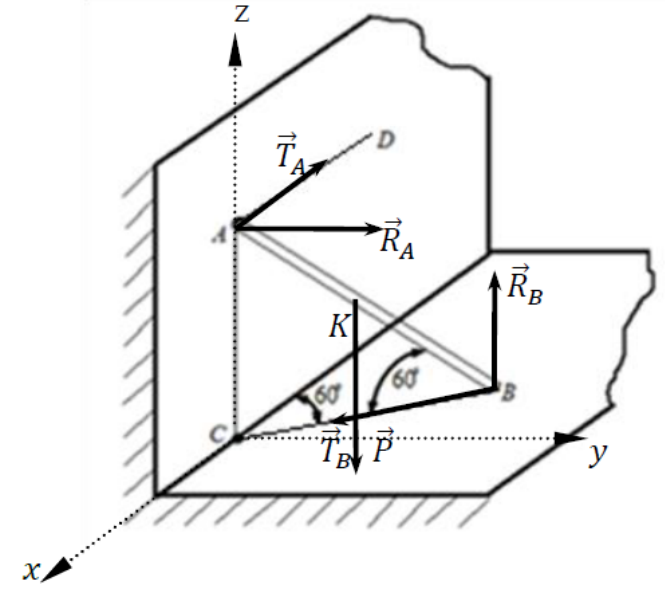

Fig.2. Design scheme with unknown forces

Since the problem is static, we introduce a spatial coordinate system, combining its beginning with the point $C$, and compose 6 static equilibrium equations:

$$
\sum_{k=1}^{n} F_{k x}=0 ; \sum_{k=1}^{n} F_{k y}=0 ; \sum_{k=1}^{n} F_{k z}=0 ; \sum_{k=1}^{n} M_{x}\left(\vec{F}_{k}\right)=0 ; \sum_{k=1}^{n} M_{y}\left(\vec{F}_{k}\right)=0 ; \sum_{k=1}^{n} M_{z}\left(\vec{F}_{k}\right)=0 .
$$

This problem can be considered only using the definitions and concepts of theoretical mechanics, applying the concepts of higher mathematics, but in case of interdisciplinary interaction, it is more preferable to implement previously studied concepts of higher mathematics. Practical working experience with students shows that this approach is more effective.

Mathematical part of the problem: it is necessary to determine the coordinates of the points of application of vectors and their projections on the coordinate axis.

At point $A(0 ; 0 ; A C)$ forces $\vec{R}_{A}\left(0 ; R_{A} ; 0\right)$ and $\vec{T}_{A}\left(-T_{A} ; 0 ; 0\right)$.

At point $B\left(-B C \cos 60^{\circ} ; B C \sin 60^{\circ} ; 0\right)$ forces $\vec{R}_{B}\left(0 ; 0 ; R_{B}\right)$ and $\vec{T}_{B}\left(T_{B} \cos 60^{\circ} ;-T_{B} \sin 60^{\circ} ; 0\right)$.

At point $K\left(-\frac{1}{2} B C \cos 60^{\circ} ; \frac{1}{2} B C \sin 60^{\circ} ; \frac{1}{2} A C\right)$ forces $\vec{P}(0 ; 0 ;-P)$.

It is not difficult to make up the first three equations of statics - just add up the corresponding projections of forces:

$$
x:-T_{A}+T_{B} \cos 60^{\circ}=0 ; y: R_{A}-T_{B} \sin 60^{\circ}=0 ; z: R_{B}-P=0 .
$$

Students have much more difficulties with equations of moments of forces relative to coordinate axes. Here higher mathematics comes to the rescue - we apply the mechanical meaning of the vector $\left[\overrightarrow{\text { rroduct }}_{a} \times \vec{F}\right]$ (the vector moment of force relative to the origin). Let's create determinants:

$$
\begin{aligned}
& \vec{M}_{C}\left(\vec{R}_{A}\right)=\left|\begin{array}{ccc}
\vec{\imath} & \vec{\jmath} & \vec{k} \\
0 & 0 & A C \\
0 & R_{A} & 0
\end{array}\right| ; \vec{M}_{C}\left(\vec{T}_{A}\right)=\left|\begin{array}{ccc}
\vec{\imath} & \vec{\jmath} & \vec{k} \\
0 & 0 & A C \\
-T_{A} & 0 & 0
\end{array}\right| ;
\end{aligned}
$$

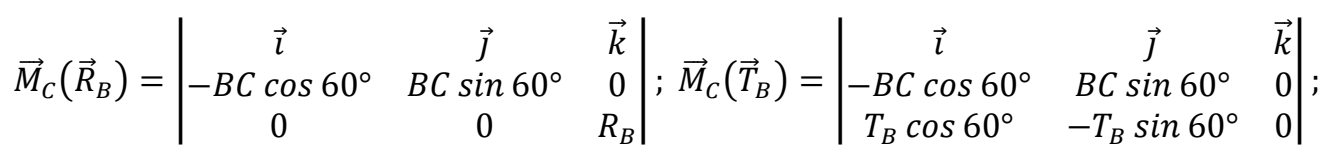

$$
\begin{aligned}
& \vec{M}_{C}(\vec{P})=\left|\begin{array}{ccc}
\vec{\imath} & \vec{\jmath} & \vec{k} \\
-\frac{1}{2} B C \cos 60^{\circ} & \frac{1}{2} B C \sin 60^{\circ} & 0 \\
0 & 0 & -P
\end{array}\right| .
\end{aligned}
$$

By revealing the determinants according to the first line and correlating the obtained minors, we can write the remaining three equations, taking into account that the obtained coefficients for unit vectors are projections of the vector moment on the coordinate axis: 


$$
\begin{aligned}
& M_{x}:-R_{A} \cdot A C+R_{B} \cdot B C \sin 60^{\circ}-P \cdot \frac{1}{2} B C \sin 60^{\circ}=0 \\
& M_{y}:-T_{A} \cdot A C+R_{B} \cdot B C \cos 60^{\circ}-P \cdot \frac{1}{2} B C \cos 60^{\circ}=0 ; \\
& M_{z}: T_{B} \cdot B C \cos 60^{\circ} \sin 60^{\circ}-T_{B} \cdot B C \cos 60^{\circ} \cos 60^{\circ}=0 .
\end{aligned}
$$

The last equation is transformed into a valid identity.

From the geometric relations, we get: $A C=B C \times \tan 60^{\circ}$.

Let's put all the equations into a system:

$$
\left\{\begin{array}{c}
-T_{A}+T_{B} \cos 60^{\circ}=0 ; \\
R_{A}-T_{B} \sin 60^{\circ}=0 ; \\
R_{B}-P=0 ; \\
-R_{A} \cdot B C \cdot \tan 60^{\circ}+R_{B} \cdot B C \sin 60^{\circ}-P \cdot \frac{1}{2} B C \sin 60^{\circ}=0 ; \\
-T_{A} \cdot B C \cdot \tan 60^{\circ}+R_{B} \cdot B C \cos 60^{\circ}-P \cdot \frac{1}{2} B C \cos 60^{\circ}=0 .
\end{array}=>\left\{\begin{array}{c}
T_{B}=2,3 \mathrm{H} ; \\
R_{A}=2 \mathrm{H} ; \\
R_{B}=8 \mathrm{H} ; \\
-2+4-2=0 ; \\
T_{A}=1,15 \mathrm{H} .
\end{array}\right.\right.
$$

Mechanical part of the problem: in system 4, the equation turned out to be a test one, allowing us to evaluate the correct form of the obtained results.

On the basis of the obtained values, we can conclude about the direction of forces: all the reactions of the supports were positive, so the direction of the vectors in the figure is correct.

In our teaching activity we propose to approach the issue of interdisciplinary integration consistently in several stages:

1) Organizing interdisciplinary and integrated lectures, thereby forming a link between the subjects of higher mathematics and theoretical mechanics. For example, lectures on "Mechanical and physical applications of a certain integral", "Solution of differential equations of the theory of small vibrations of a mechanical system with 1 and 2 degrees of freedom".

2) Practical classes with students can also be organized by methods of interdisciplinary communication. For example, obtaining equations of equilibrium of bodies with the help of determinants will not only fix the mathematical part of the problem, but also delve deeper into the concept of the moment of force relative to the axis.

3) Model and calculation-graphical work is one more of the most effective ways for interdisciplinary integration. It allows not only to consider the tasks of theoretical mechanics from the point of view of the theoretical component, but also to demonstrate the application of mathematical apparatus to the study of the problem. Mathematical tasks with a physical component are considered when analyzing case problems that are included in the calculation and graphic work on higher mathematics and in the tasks of the 3 block of Internet testing.

4) Organization of students' team work for joint implementation of educational and scientific tasks in the discipline. This type of independent work allows you not only to master the specifics of your future profession, but also develops your communication skills, develops skills of team interaction. It is possible to organize such work of students using the following methods: preparing and carrying out mathematical battles; performing research teamwork on the following interdisciplinary topics as: economic application of linear algebra elements, geometric and physical application of derivatives and integrals in machine building and power engineering, and investigation of the movement of mechanical systems, etc.

5) Active and interactive learning using complex computer programs, computer applications, or the Moodle system. This method is well applied in end-to-end training, for a smooth transition from one subject to another by compiling tasks for the disciplines "Mathematics" and "Theoretical mechanics". In turn, we note that the Moodle system (Seliverstova, 2017, p. 183) does not require specialized laboratory equipment. And various kinds of applications can be used to pass the current test in the form of testing (Volodina, 2017, p. 60). Despite the fact that such a method of teaching takes a fairly large amount of time for the teacher to prepare/form tests, we came to the conclusion that this approach allows us to track quickly the absorption of the discipline by students. 


\section{MAIN RESULTS AND CONCLUSIONS}

Interdisciplinary integration in the learning process can be observed even at primary school when studying the following academic disciplines as Mathematics and World around us, Mathematics and Literature reading, Mathematics and Music, etc. In I. N. Ulyanov Chuvash State University, an active professional orientation work is carried out in the framework of the project "Days of interdisciplinary integration". Students of various age groups are shown on practical examples, case problems, case situations a close relationship of Mathematics and Economics, Mathematics and Physics, Mathematics and Computer science. Also the Institute conducts various kinds of intellectual games (Vasilyeva, 2018, p. 199). Continuous and step-by-step education "School-University" at each stage makes it possible to solve the problems of not only the educational program, but also the development and education of modern pupils, and in future, of students. Each stage is built on common principles and methods and is aimed at the final goal - professional competence of the specialist.

The implementation of this approach is impossible without the joint work of teachers in drawing up programs, developing the content of disciplines, detailed study of the presentation of educational material, to assess knowledge and skills. The integral implementation of the idea of interdisciplinary implementation in the entire educational process is very important, it can be observed in the Ishikawa diagram or "fish skeleton" (Gartfelder, 2018, p. 234). And any skeleton, as we know, consists of small branches or components, which can be considered as an inseparable pedagogical process that develops the personality of a future professional.

It is necessary to use regularly and gradually integrated tasks in practical classes and independent works of students, because it is practice that allows not only to consolidate the knowledge gained, but also to "feel" the very essence of the subject being studied.

As a result of the study of interdisciplinary communication, we draw the following conclusion: the ability to apply knowledge from different disciplines in aggregate, transfer ideas and methods from one science to the other, is an essential condition for the successful preparation of students for future professional activities and their implementation as highly qualified specialists. Such an approach to the implementation of the educational process undoubtedly has a great research potential, since it allows to prepare a specialist who meets all the modern requirements of the labor market.

\section{REFERENCE LIST}

Khutorskoy A.V. Key competencies as a component of the personality-oriented education paradigm / A.V. Khutorskoy // Public Education. 2003. № 2. Pp. 55-61.

Troeshestova D.A, Vasilyeva E.V. Pedagogical development of students' professional competence // Akmeology, 2014. No. S3-4. Pp. 167-168.

Malysheva, O.S., Gilvanov R.R. Problems of formation of professional competencies of students of technical universities // Modern problems of science and education. 2013. No. 6. P.304.

Ilina I.I. Formation of competence in the field of information and communication technologies for bachelors in the field of radio electronics and automation // Collection of reports and scientific articles of the AllRussian Scientific and Practical Conference (dedicated to the 50th anniversary of. I. Ulyanov Chuvash State University.) , 2018. Pp. 481-486.

Volodina E.V., llina I.I. The development of mathematical competence in technical students // Mathematical models and their applications. Cheboksary, 2017. Pp.110-118.

Troeshestova D.A., Vasilyeva E.V. The development of professional competences of students in the study of theoretical mechanics // Mechanics: current state, problems and prospects. Collection of articles of the All-Russian scientific-practical conference, 2014. Pp. 132-136.

Gartfelder V.A., Sekletina L.S. Integration of regional potentials for engineering training // Network interaction as an effective technology for training personnel materials of the All-Russian (with international participation) scientific and methodological conference. Volga State University of Technology. 2015. Pp. 31-34.

Gartfelder V.A. Integration of potentials of industrial enterprises and educational institutions on the example 
of the engineering department of I.N. Ulyanov Chuvash State University // Intellect. Innovation. Investments. 2011. No. 1. Pp. 194-196.

Vasilyeva L.N., Merlina N.I., Svetlova N.I. Interdisciplinary integration of mathematics and computer science in the system of formation of professional and mathematical competence of students of technical training areas // Vector of Science of Togliatti State University. Series: Pedagogy, Psychology. 2015. № 2 (21). Pp. 19-23.

Perehozheva E.V., Shershneva V.A. Didactic aspects of interdisciplinary integration in a technical university // Bulletin of Krasnoyarsk State Pedagogical University. V.P. Astafieva. 2012. № 2. Pp. 124-127.

Seliverstova L.V. Some problems of teaching higher mathematics to students of the Faculty of Mechanical Engineering // Mathematical Bulletin of universities and universities of the Volga-Vyatka region. 2015. №. 17. Pp. 150-154.

Brycheva S.N., Sveklova O.V., Farafonova A.G. Interactive teaching methods as a means of forming and improving the universal competences of technical students of chu in the teaching of a foreign language // Linguistics, linguodidactics, translation studies: current issues and prospects for research: a collection of materials of the International Scientific and Practical Conference. Ministry of Education and Science of the Russian Federation; Federal State Budgetary Educational Institution of Higher Professional Education " I.N. Ulyanov Chuvash State University.". 2015. Pp. 173-182.

Seliverstova L.V. Point-rating system for assessing the quality of student training // Collection: Mathematics. Education. 2013. P. 272.

Merlina N.I., Seliverstova L.V., Yarduhina S.A. Point-rating system for assessing the quality of student achievement // Baltic Journal of Humanities. 2015. № 3 (12). Pp. 58-61.

Konstantinova I.O., Mytnikov A.N. Development of a point-rating system for assessing students' knowledge // Collection of Scientific Works: Computer Science and Computer Engineering Collection of Scientific Works. Cheboksary, 2018. Pp. 125-131.

Seliverstova L.V., Kartuzova T.V. The use of elements of the MOODLE system in the point-rating system for assessing student performance // Azimuth of scientific research: pedagogy and psychology. 2017. Vol. 6. No. 1 (18). Pp. 181-183.

Sinkina E.A. Formation of professional competencies through the use of multi-level tasks and tasks of professional orientation // Bulletin of PNRPU. Machine building, materials science. 2012. V. 14. №. 3. Pp. 109-113.

Mytnikova E.A. Methodical development of an integrated lesson of computer science and mathematics on the topic "Branch operators" // Collection of reports and scientific articles of the All-Russian Scientific and Practical Conference (dedicated to the 50th anniversary of I.N. Ulyanov Chuvash State University): Status and prospects of development of IT education. 2018. Pp. 417-422.

Sinkina E.A. The role of general professional disciplines in formation of professional competence of students of technical universities // Bulletin of Perm State Technical University. Machine building, materials science. 2011. Vol. 13. № 2. Pp. 116-119.

Zakharov O. V. Minimization of errors in shape forming during centerless abrasive treatment. Saratov: SSTU, 2006, 152 p. (in Russian)

Volodina E.V., Ilina I.I., Timofeeva N.N. The use of modern mobile applications in the process of learning and verification of residual knowledge of students // Collection of scientific papers: Computer science and computer technology. Dedicated to the 50th anniversary of I.N. Ulyanov Chuvash State University. Cheboksary, 2017. Pp. 57-62.

Vasilyeva E.V., Seliverstova L.V. Development of some personal and meta-subject competencies of secondary and general education using team math games // Baltic Humanitarian Journal. 2018. T. 7. No. 1 (22). Pp. 197-200.

Gartfelder V.A., Yanyushkin, Sekletina L.S., Lobanov D.V. Problems and prospects of training engineering personnel for the engineering industry. Vestnik IzhSTU. M.T. Kalashnikov. 2018. T. 21. No. 3. Pp. 230-235. 